\title{
Direct Measurement of the Impact of Teaching Experimentation in Physics Labs
}

\author{
Emily M. Smith $\odot,{ }^{1,2}$ Martin M. Stein, ${ }^{1}$ Cole Walsh, ${ }^{1}$ and N. G. Holmes ${ }^{1}$ \\ ${ }^{1}$ Laboratory of Atomic and Solid State Physics, Cornell University, Ithaca, New York 14853, USA \\ ${ }^{2}$ Department of Physics, Colorado School of Mines, Golden, Colorado 80401, USA
}

(Received 19 March 2019; revised manuscript received 16 November 2019; accepted 13 December 2019; published 10 February 2020)

\begin{abstract}
While there have been many calls to improve the quality of instructional physics labs, there exists little research on the effectiveness of lab instruction. This study provides a direct comparison between labs that have goals to reinforce physics content to those that emphasize experimentation skills. In this controlled study, all students attended the same lecture and discussion sections, had the same homework and exams, but attended labs that had one of two aims: teaching experimentation or reinforcing content. We compare students' engagement with experimentation during the lab as well as the impacts on students' exam performance and attitudes and beliefs about experimental physics. We find no measurable differences between lab conditions on students' exam performance. Nonetheless, we find measurable and significant improvements in students' engagement in expertlike experimentation practices and attitudes and beliefs about experimental physics for students in the experimentation labs. The benefits of the experimentation labs are stable across two subsequent semesters of implementation, as measured via standardized assessments. The results provide direct evidence of the extensive benefits of using labs to teach experimentation while directly demonstrating that shifting instructional goals and structure in labs can occur without cost to performance on course exams.
\end{abstract}

DOI: 10.1103/PhysRevX.10.011029

Subject Areas: Interdisciplinary Physics

\section{INTRODUCTION}

There are extensive calls to get students actively engaged in their learning during class time and to provide students with authentic science experiences [1-4]. Instructional labs are ideal environments in which to provide these experiences, and many organizations recommend replacing traditional lab courses with more discovery-based methods [5]. However, lab instruction has been slow to change, and one argument is that shifting instructional goals away from reinforcing content and toward teaching experimentation negatively impacts students' content knowledge.

Previous work suggests that traditional labs (which we characterize as being highly structured and aiming to reinforce content from lecture) do not measurably contribute to students' content knowledge [6,7], do not engage students in the decision-making and critical thinking behaviors of an experimentalist [8], and deteriorate students' attitudes toward and perceptions of experimentation $[9,10]$. The research thus far, however, provides only predictions for the benefits of shifting to labs aiming to

Published by the American Physical Society under the terms of the Creative Commons Attribution 4.0 International license. Further distribution of this work must maintain attribution to the author(s) and the published article's title, journal citation, and DOI. teach experimentation; direct measurements have not been performed in previous studies.

For example, studies of the impact of labs on students' content knowledge compare students enrolled in courses with optional labs: That is, they compare taking the lab with not taking the lab on student performance $[6,7,11]$. While the selection effects are accounted for, this study does not directly demonstrate the effect of labs explicitly intended to develop experimentation skills. The studies of the impact of labs on attitudes and perceptions of experimental physics compare students enrolled in different types of courses offered by different institutions $[9,10]$. Large samples are used to account for variability between student populations, courses, instructors, and institutions, but a direct, controlled comparison has not been done.

In this study, we provide a direct, controlled measurement of the impacts of a full semester of experimentationfocused labs on multiple dimensions of students' learning: engagement with experimentation, content knowledge, and attitudes and beliefs about experimental physics. We apply research-validated instruments and techniques to perform a controlled study comparing the effects of lab instruction that aims to reinforce the content from lecture with instruction that aims to teach experimentation skills. We measure the quality of students' engagement with experimentation during a lab to ensure that the comparisons are valid (that is, to check whether the instructional intent of 
the experimentation labs is realized in students' activities). We also include additional semesters of instruction beyond the controlled study to test the stability of the results into subsequent semesters with new students and instructors. We find that exam scores are indistinguishable between lab conditions, but labs focused on experimentation positively and consistently affect students' attitudes and beliefs about experimentation and engage students in expertlike experimentation behaviors.

\section{PREDICTIONS FROM PRIOR WORK}

Results from previous studies provide predictions for the controlled experiment. From prior literature on students' learning in labs, we isolate three dimensions for our study: (i) engagement with experimentation, (ii) exam performance, and (iii) attitudes and beliefs about experimental physics.

\section{A. Students' engagement with experimentation}

Our first prediction is that labs designed to teach experimentation compared to those designed to reinforce content knowledge would provide students with higherquality experimentation experiences. The comparison evaluates whether the instructional intent aligns with student outcomes and provides a validity check for the remaining comparisons.

Researchers previously found that, in labs designed to engage students in experimental design and iterative and reflective decision making, students frequently engage in expertlike scientific behaviors [8,12-14]. Additionally, students in more open-ended labs choose to spend more time in the lab compared to those in more structured labs [15], and full engagement is more frequent when students have a choice in labs [16]. Students who engage in experimental design also spend more time sense making compared to their peers who are provided with procedures [15,17].

From these previous studies, we identify two subpredictions related to students' engagement with experimentation: In labs designed to teach experimentation, students would (a) engage more in experimentation behaviors and (b) spend more time in the labs than in labs designed to reinforce content.

\section{B. Exam performance}

Our second prediction is that exam performance would not be affected by shifting the goals of lab instruction to teach experimentation rather than to reinforce traditional physics content [18]. A common concern from faculty in changing their lab curriculum is the effect of removing or reducing exposure to physics content. Some may argue that teaching experimentation in labs should not come at the detriment to students' learning of traditional physics content.
In multiple introductory physics courses at several institutions, there is no measurable added value for labs in reinforcing physics content as measured by exam performance $[6,7,11]$, even when isolating conceptual questions directly related to the lab material. Other work has found no difference in exam performance between students who design their own procedures and those who are provided with procedures $[15,19]$. These studies suggest that, in combination with lecture, discussion sections, homework, and other course components, lab instruction has little impact on students' exam performance.

The lack of measurable effects from labs is not simply an issue of measurement precision. Studies repeatedly demonstrate that there exist performance differences on exams and concept inventories between other subpopulations of students. For example, many studies identify performance differences between men and women on concept inventories in introductory mechanics [20-28] and on physics exams $[21,22]$ (though this result has not been universal $[20,23,24])$.

In summary, from prior studies, we predict that shifting the goals of lab instruction away from course content and toward experimentation would not affect students' exam performance. We also test the precision of the contrast between lab types by comparing to effects based on students' genders and majors.

\section{Attitudes and beliefs about experimental physics}

Our third prediction is that experimentation labs would improve (or, at minimum, not decrease) students' attitudes and beliefs about experimentation. A common goal in labs is to engage students in authentic experimentation, often as a means to improve their understanding of the nature of science and develop transferable skills. Researchers use various surveys to probe different dimensions of students' attitudes and beliefs about experimental physics.

One such survey, the Colorado Learning Attitudes about Science Survey for Experimental Physics (E-CLASS), probes students' personal attitudes and beliefs about experimental physics. Students are asked to indicate the degree to which they agree with statements such as "when I am doing an experiment, I try to make predictions to see if my results are reasonable" [29,30]. On each item, students separately answer what they personally believe and how they think an expert would respond.

Labs designed to teach experimentation skills and those with open-ended tasks are shown to improve students' E-CLASS scores (indicating improved alignment with expertlike attitudes and beliefs about experimental physics) when compared to those designed to teach physics content [10] and with highly structured activities [9]. In a comparison of two lab curricula at the same institution, there is no shift in E-CLASS scores for students in labs that aim to teach experimentation skills and a negative shift for structured labs aiming to reinforce content $[31,32]$. 
However, the students in each type of lab course come from different courses [31,32] or institutions $[9,10]$ rather than controlled comparisons within the same population.

Based on these results, we expect that, in highly structured labs that reinforce physics content, students' E-CLASS scores would have an overall negative shift. In labs designed to teach experimentation, we expect students' E-CLASS scores would undergo a small overall positive shift. Additionally, we expect to observe gendered and majored differences in E-CLASS scores similar to those that had been previously reported [33].

Separate from the E-CLASS, Hu and Zwickl developed an open-ended survey to gauge students' personal epistemology about labs and experimental physics [34-36]. We refer to this survey as the lab epistemology survey (LES) to distinguish it from the E-CLASS. The LES poses six questions about students' perceptions of experimentation and labs, such as "why are experiments a common part of physics classes?," "in your opinion, what defines a scientific theory?," and "how do you know if an experimental result is acceptable or trustworthy?"

Prior studies of the LES compare responses from introductory and advanced physics students and find that introductory students tend to view physics labs as hands-on activities that reinforce or supplement the physics concepts introduced during lecture [35], consistent with prior literature [37]. However, graduate students are more likely to state that experiments are fundamental to physics as a science and more frequently describe a scientific theory as having explanatory or predictive power [35]. Additionally, introductory students tend to evaluate the trustworthiness of experimental results through comparisons with theory, while graduate students tend to rely on multiple criteria including the ability to repeatedly obtain results, evaluate uncertainty, and carry out high-quality work [36].

Based on these studies, we expect that, in highly structured labs that reinforce physics content knowledge, students' responses to the LES would differ from students in labs designed to teach experimentation. The previous research does not inform the differences specifically, but we predict students' responses would align with their experiences.

In summary, we identify two subpredictions related to students' attitudes and beliefs about experimentation: (a) Students' attitudes and beliefs about experimental physics would remain stable or become more expertlike in labs intended to teach experimentation and become less expertlike in those that reinforce physics content, and (b) students' epistemologies about experimental physics would align with their different experiences in labs.

\section{METHODS}

To test these predictions, we perform a controlled study to compare students in the same lecture course but in different accompanying lab courses. We refer to the different labs as content-reinforcement and experimentation labs. We also include data from subsequent semesters with the experimentation labs to test the stability of these results. We describe the design of the study, participants, lab types, data sources, and analysis methods in this section.

\section{A. Participants}

Participants were students enrolled in a first-semester, introductory calculus-based physics course, focusing on mechanics and special relativity. Most students in this course have previously taken college-level physics in high school (e.g., Advanced Placement), and were expected to be concurrently enrolled in a multivariable calculus course. Data were collected across three semesters of this course.

In the first semester (semester 1), all students attended the same lectures and discussion sections, had the same problem sets and exams, but attended one of two different types of labs. Students selected their lab section without knowing the type of instruction they would receive, providing approximately random assignment between lab conditions. This assignment also controls for the impact of lecture, discussion sections, problem sets, and other components of the course. No students switched lab sections after announcements explaining that the lab sections were using different materials nor after participating in the first lab activity. There were five lab sections, each with approximately 20 students: Three of the sections used content-reinforcement labs, and two of the sections used experimentation labs. Students were graded for participation in and completion of each lab activity.

For the second and third semesters (semesters 2 and 3, respectively), we repeat a selection of the measures in the same course when all lab sections are experimentation labs. We select only measures that are comparable across different implementations (e.g., standardized diagnostics and analysis of lab notes). We do not analyze measures that vary from course to course (e.g., exams). After semester 1, several changes were made to the structure of the experimentation labs including the addition of undergraduate teaching assistants, grading and providing feedback on the quality of lab notes, and replacement of one of the lab activities. Data from semesters 2 and 3 serve to address a common concern with course transformations that the results from the first intervention are not maintained as new instructors take on the material.

Students self-reported their demographic information on a survey at the end of the semester as summarized in Table II. Throughout this paper, the number of participants fluctuates due to students' consent choices for each data source, and some data are missing due to exemptions from assignments. A large fraction of the participants in this study intended to major in physics [38]. Between contentreinforcement and experimentation labs in semester 1 , 
the fraction of physics majors is different. Therefore, our statistical analyses control for students' majors.

\section{B. Conditions}

Students were enrolled in lab courses designed either to reinforce the content from lecture or to teach experimentation skills. Though the structure of the labs differs significantly, our research questions probe the impacts of the different aims of lab instruction (content-reinforcement or teaching experimentation). We, therefore, include necessary detail about the conditions to meaningfully interpret the results. Additional details about the conditions are provided in the Appendix A 1.

The content-reinforcement labs are designed explicitly and exclusively to reinforce physics content knowledge by providing students with hands-on experiences with the phenomena introduced in the lecture part of the course. The lab schedule closely aligns with the order and timing of lecture content, as per the ordering in Table I. Students follow a manual that outlines the steps in the experimentation process and answer questions about the phenomena that they observe. The structure of the lab activities is consistent throughout the semester. The instructions always provide students with the experimental procedures and explanations of the relevant physics. The students answer questions in printed worksheets that are submitted by the end of the lab period. The questions aim to engage students in sense making about the relevant physics concepts.

The experimentation labs are designed to develop students' skills associated with the process of experimental physics with no intention to reinforce students' content knowledge. As shown by the ordering of labs in Table I, the number of content areas associated with the labs is significantly less than in the content-reinforcement labs. Structurally, the aim to develop students' experimentation skills is implemented in the labs by requiring students to make decisions about the design, analysis, and extensions of their experiments. Details about the development of the learning goals for these labs and how activities are structured to achieve them can be found in Ref. [39]. As the semester progresses, structure is faded from the experimentation lab instructions, leaving more of the decision making to students, such as in Ref. [8]. For example, in the pendulum I and II labs (adapted from the activity described in Ref. [40]), students are provided with a model to test, prompted to iterate and extend their investigations, and cued to apply previously introduced statistical methods. However, students are expected to decide how to test the model, how to improve their measurements, and how to extend their investigations, leaving students with control over many experimentation decisions. In the project lab at the end of the semester, groups develop an investigation that could extend any of the preceding labs, and so nearly all experimentation decisions are left to students, including the research question. Throughout the lab, students are expected to document their processes and results in electronic lab notebooks. They submit one set of notes per group by the end of the lab period. Instructional materials similar to those used in the experimentation labs can be found in Ref. [41].

\section{Data sources}

\section{Students' engagement with experimentation}

We identify two variables that speak to students' engagement with experimentation in lab: (i) the amount of time they spend and (ii) the types of experimentation behaviors in which they engage. These measures serve both as results of the impact of the different lab treatments but also as validity checks on the conditions.

Observers attended each of the lab sections for five out of the nine weeks of the experimentation labs and four out of the nine weeks of the content-reinforcement labs in semester 1. Every $5 \mathrm{~min}$, they recorded each student's behavior using an observation protocol (see Ref. [42]) and marked the time segment at which the student left the lab for the day. Appendix A 2 provides details for how these

TABLE I. Order of lab activities for each lab condition. We use abbreviations for lab activities (in parentheses) later in the paper to avoid confusion about the differences in weeks between experimentation labs in semesters 1,2 , and 3 .

\begin{tabular}{|c|c|c|c|}
\hline \multirow[b]{2}{*}{ Week } & \multicolumn{2}{|c|}{ Semester 1} & \multirow{2}{*}{$\frac{\text { Semesters } 2 \text { and } 3}{\text { Experimentation }}$} \\
\hline & Content reinforcement & Experimentation & \\
\hline 1 & Measurement and uncertainty & Pendulum I (pend. I) & Pendulum I \\
\hline 2 & Dynamics of $1 \mathrm{D}$ motion & Pendulum II (pend. II) & Pendulum II \\
\hline 3 & Newton's laws and dynamics & Terminal velocity I (TV I) & Bouncing ball \\
\hline 4 & Force laws & Terminal velocity II (TV II) & Terminal velocity I \\
\hline 5 & Energy exchanges & Hooke's law I (HL I) & Terminal velocity II \\
\hline 6 & Bounce collisions & Hooke's law II (HL II) & Hooke's law I \\
\hline 7 & Stick-together collisions & Collisions & Hooke's law II \\
\hline 8 & Angular momentum and precession & Project lab I (proj. I) & Project lab I \\
\hline 9 & Free and driven oscillations & Project lab II (proj. II) & Project lab II \\
\hline
\end{tabular}


TABLE II. Student demographics in the different conditions and semesters. Students self-reported their demographic information on an end-of-semester survey, but not all students answered all demographic questions. Several additional descriptors for all categories are included on the survey (e.g., additional options for gender). The underrepresented races and ethnicities category is defined relative to the physics discipline.

\begin{tabular}{|c|c|c|c|c|c|}
\hline \multirow[b]{2}{*}{ Category } & \multirow[b]{2}{*}{ Descriptor } & \multicolumn{2}{|c|}{ Semester 1} & \multirow{2}{*}{$\frac{\text { Semester } 2}{\text { Experimentation }}$} & \multirow{2}{*}{$\frac{\text { Semester } 3}{\text { Experimentation }}$} \\
\hline & & Content-reinforcement & Experimentation & & \\
\hline \multirow[t]{4}{*}{ Race/ethnicity $^{\mathrm{a}}$} & White & $45 \%(n=23)$ & $68 \%(n=27)$ & $62 \%(n=21)$ & $49 \%(n=45)$ \\
\hline & Asian & $43 \%(n=22)$ & $28 \%(n=11)$ & $35 \%(n=12)$ & $40 \%(n=36)$ \\
\hline & $\begin{array}{l}\text { Underrepresented races } \\
\text { and ethnicities }\end{array}$ & $10 \%(n=5)$ & $5 \%(n=2)$ & $9 \%(n=3)$ & $13 \%(n=12)$ \\
\hline & Unknown & $8 \%(n=4)$ & 0 & $3 \%(n=1)$ & $5 \%(n=5)$ \\
\hline \multirow[t]{4}{*}{ Major } & Physics or engineering physics & $74 \%(n=40)$ & $49 \%(n=21)$ & $24 \%(n=8)$ & $66 \%(n=57)$ \\
\hline & Other science or engineering & $13 \%(n=7)$ & $26 \%(n=11)$ & $41 \%(n=14)$ & $24 \%(n=21)$ \\
\hline & Other & $4 \%(n=2)$ & $19 \%(n=8)$ & $35 \%(n=12)$ & $6 \%(n=5)$ \\
\hline & Unknown & $9 \%(n=5)$ & $7 \%(n=3)$ & 0 & $5 \%(n=4)$ \\
\hline \multirow[t]{3}{*}{ Gender } & Women & $19 \%(n=10)$ & $19 \%(n=8)$ & $29 \%(n=10)$ & $32 \%(n=28)$ \\
\hline & Men & $81 \%(n=44)$ & $81 \%(n=35)$ & $71 \%(n=24)$ & $67 \%(n=58)$ \\
\hline & Unknown & 0 & 0 & 0 & $1 \%(n=1)$ \\
\hline
\end{tabular}

${ }^{\mathrm{a}}$ Some students self-identify with more than one descriptor.

observations are used to calculate the average time students spend in lab.

By design, students in the experimentation labs are expected to engage in iterative and reflective experimentation behaviors associated with critical thinking as defined in Ref. [8]. In the experimentation labs in semesters 1 and 2, we used groups' lab notebooks to identify the number of groups that recorded engagement in the following behaviors (code descriptions in Ref. [8]): (1) proposing and carrying out changes to their investigations and (2) identifying and interpreting disagreements between data and a provided model. Explicit prompts to propose and carry out changes to investigations (behavior 1) are given to students in the early parts of the semester, and the prompts are faded as the semester progresses. The fading facilitates evaluating whether students learn to engage in the behaviors without explicit prompting. Additionally, two labs (pendulum and Hooke's law) are deliberately designed so that students could identify and interpret disagreements between data and a model provided in the lab instructions (behavior 2); with sufficient precision, the limitations of the models are measurable and could be interpreted through further experimentation. In the other experimentation labs, potential disagreements are driven by students' extensions to their investigations and are not deliberately integrated into the lab activities.

The content-reinforcement labs use "fill-in-the-blanks" worksheets rather than lab notebooks. We identified one prompt in one activity that corresponds to identifying and interpreting disagreements between data and a model (behavior 2), and this disagreement is explained in the manual prior to the question. For this question, we establish the fraction of students who identify and/or interpret the disagreement. Most other questions ask about physics content, and so we assume that students spent the majority of their time focused on conceptual understanding probed by the prompts rather than making decisions about the experimental design or data. This assumption agrees with other research that measures what students handle throughout the labs [42].

\section{Exam performance}

In semester 1, students selected into their lab sections without knowledge of the conditions, so we expect the most prominent selection effect to be students' course schedules. This quasiexperimental design allows us to directly compare students' performance on course exams. Because the explicit intent of the content-reinforcement labs is to reinforce the content from lecture, the exams and the corresponding scores assigned by course instructors serve as the most ecologically valid measure of that goal.

We use linear mixed models to test whether lab conditions correlate with exam performance across three exams during the course (two midterms and a final). We treat students' scores as repeated measures of their exam performance, students' major, gender, and lab condition as fixed effects, and fit random intercepts for each student. We select this set of predictors due to the differences between the proportion of majors between conditions and because prior literature measures performance differences between men and women on course exams [20-22]. By using random intercepts for each student, we control for random fluctuations in individual students' exam scores. However, the data do not have sufficient statistical power to capture variations in improvement over time through random slopes. 
We test two models: Model 1 uses the outcome variable of exam score predicted by fixed effects of major, gender, and lab condition, and model 2 uses the same outcome variable and fixed effects but also includes interactions between lab conditions and exam. This interaction aims to test whether there is a difference between content-reinforcement and experimentation labs on earlier versus later exams, as suggested by descriptive statistics. As a confirmatory step, we also perform a mixed model type III analysis of variance (ANOVA) using Satterthwaite's approximation to evaluate the overall variable effects from the mixed model. Additional details are provided in Appendix A 3.

\section{Attitudes and beliefs about experimental physics}

Students' attitudes and beliefs about experimental physics are measured through the E-CLASS and the LES. We use conventional analyses for the E-CLASS but make small modifications to analyses of the LES to improve its local description of students' responses.

We administered the E-CLASS at the beginning and end of each semester in this study. Only students who completed both pre- and postsurveys and who correctly answered the filtering question are included in the analyses. We use the convention for reporting E-CLASS scores such that possible scores range from -30 to 30 [29]. For each of the 30 Likert items, a response that is consistent with the majority of experts' responses is assigned a value of 1 , each inconsistent response is assigned -1 , and a neutral response is assigned 0 [29]. A shift refers to the difference between post- and prescores. Students in this study have relatively high prescores compared to students in first-year lab courses in previous studies $[9,10,29,33]$. However, the students in the experimentation labs begin, on median, with higher scores than the students in content-reinforcement labs.

We perform multiple linear regressions, and, as in the exam analysis, model variables are selected from previous literature and demographic differences between conditions. All models include lab condition, gender, and major as predictors $[9,10,33]$. To account for high prescores and different proportions of physics majors in each lab condition, we include interactions in two of the selected models. Additional details are provided in Appendix A 4 a.

To test the stability of E-CLASS results in subsequent implementations of the experimentation labs, we treat labs as four distinct conditions (content-reinforcement labs in semester 1 , experimentation labs in semester 1 , experimentation labs in semester 2, and experimentation labs in semester 3) and retest the models.

During week 8 in semester 1, we administered the LES as a prelab assignment to all students; the students received full credit for completing the LES regardless of their responses. Hu and Zwickl developed a code book based on students' responses at different institutions [34-36], and we made modifications to the code book to capture the responses of the students in this study. We removed all identifying information about the students, and then two authors iteratively coded all responses to the LES so that we were unaware of the students' identity and lab condition until reaching full agreement. After reaching full agreement, we identified the lab condition associated with each response to compare across lab conditions. Additional details about the analysis are provided in Appendix A 4 b.

\section{RESULTS}

In this section, we report the results from each of the analyses comparing students enrolled in experimentation and content-reinforcement labs, testing our predictions from previous literature. Our results cannot distinguish students' exam performance due to lab conditions. However, we find measurable differences in how students engage in labs and their attitudes and beliefs about experimental physics that we attribute to lab conditions.

\section{A. Students' engagement in experimentation}

We expect, from the design of the labs, that students' engagement would differ between the content-reinforcement and experimentation labs. Our analyses indicate that the students in the experimentation labs spend more time in labs and frequently engage in experimentation behaviors.

\section{Time spent in the lab}

Although the lab sessions for both conditions are 115 min long, students in the experimentation labs spend significantly more time in lab $(118 \pm 4 \mathrm{~min})$ than students in the content-reinforcement labs $(91 \pm 7 \mathrm{~min}$, means reported with standard errors). We attribute these differences (Welch's $t$ test: $t=3.17, p<0.05 ; d=2.18$ ) to the structure of the activities in each type of lab. In the content-reinforcement labs, students can work as quickly as possible to complete all the tasks and answer all the questions in the lab manual; the larger standard error for students in the content-reinforcement labs demonstrates the greater variability in students' time to complete the lab activities. In contrast, in the experimentation labs, students are expected to iterate and improve their measurements and to extend their investigations, without a definitive end point. For that reason, nearly all students stay for the allocated time. This result suggests that the experimentation labs engage students in the activities associated with experimentation, as designed. Table IX in Appendix A 2 lists the mean time students spend in lab during each of the observed lab sessions to provide context for the variations in time for different labs.

\section{Experimentation behaviors}

Figure 1 shows the fraction of groups in the experimentation labs that record two experimentation behaviors: iterating on their experiment and identifying and interpreting disagreements between data and a given model. 


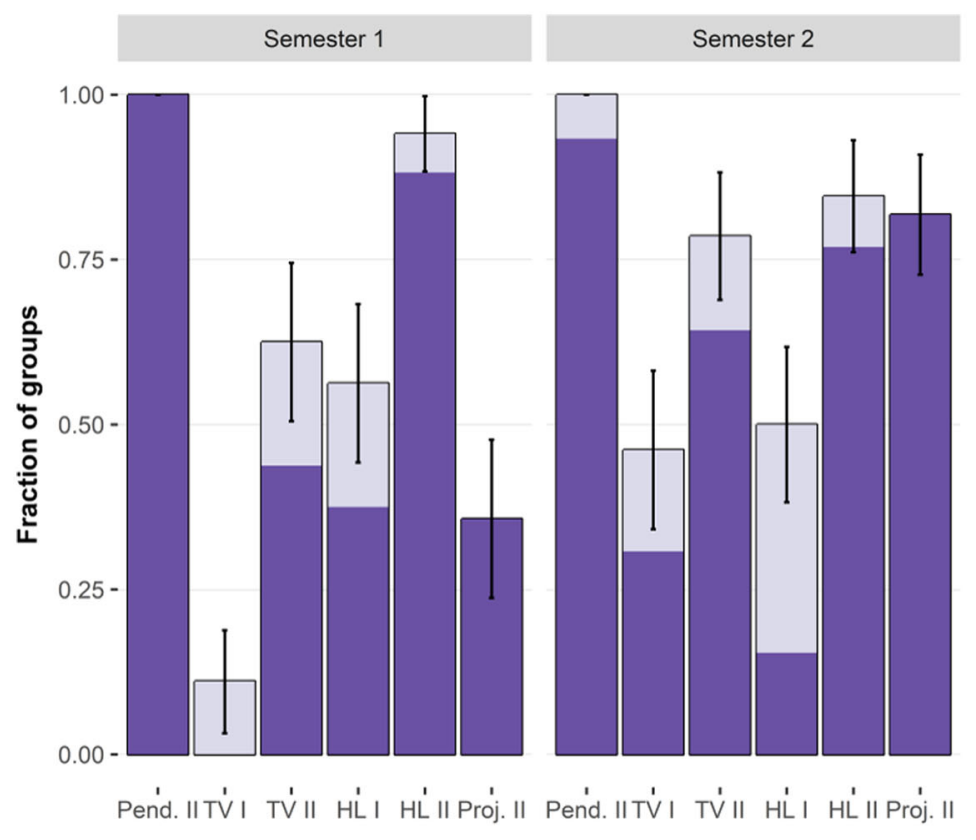

Propose only $\quad$ Propose \& change

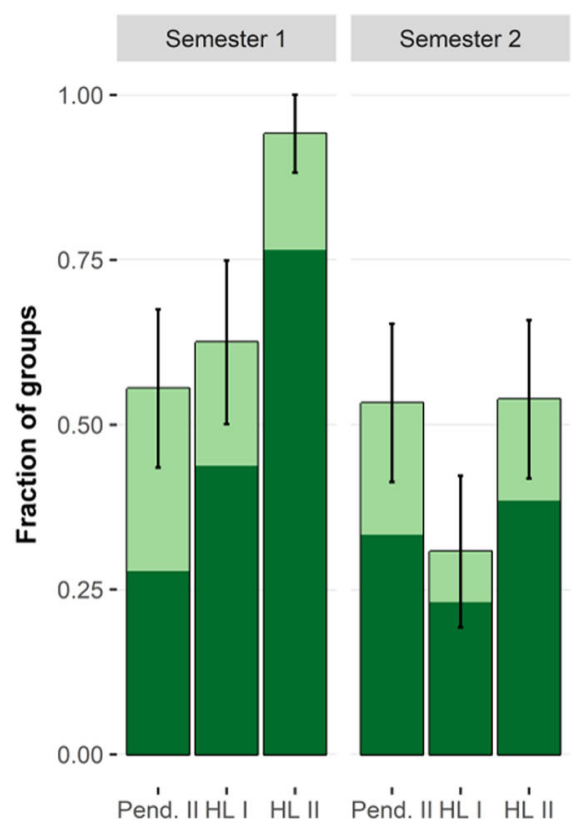

Identified

Identified \& interpreted

FIG. 1. The fraction of groups in semesters 1 and 2 proposing and carrying out changes to their experiments (left, purple) and identifying and interpreting model disagreements (right, green) in their lab notes indicates that students extensively engage in these behaviors, with variation across activities and semesters. Lab activities (indicated on the $x$ axis) are ordered sequentially and correspond to weeks listed in Table I.

The results indicate that, on average, students' engagement in these behaviors is as good as or better than seen in previous work using similarly structured labs [8]. In both semesters, students frequently propose and incorporate changes to their experiments, even when structure prompting them to do so is faded in the later parts of the semester. They are also more likely to identify and interpret disagreements between data and a given model at the beginning of the semester than students in previous studies [8]. For both measures, the effects over time and between semesters varies, likely due to the structure of individual lab activities each week and the behaviors of different instructors each semester (discussed in more detail in Appendix B 1).

In the content-reinforcement labs, we found one question that explicitly asks students to interpret a disagreement between their data and a given model. Extensive detail about this issue is provided in the introduction to the lab activity. Approximately a third of students identify that the data and model disagree $(31 \%, n=15)$ and provide reasoning to explain the discrepancy $(27 \%, n=13)$. Even with explicit prompting and explanation, fewer students engage in this experimentation behavior when compared to groups that are unprompted to do so in the experimentation labs. Furthermore, few students explain the disagreement using explanations about the limitations to the model that are provided earlier in the lab instructions. Instead, most students cite poor data or equipment as the reason for the discrepancy between their data and the model.

\section{B. Exam performance}

The results of the analyses of student exam performance are shown in Table III and, overall, find no measurable difference between lab conditions. Both mixed models equivalently explain the data (see model comparison criteria in Table III). In both models, the greatest predictor of exam performance is students' gender; men systematically outperform women. The effect of lab conditions is smaller than that of gender but measured with the same precision, as indicated by the similar standard errors on the associated coefficients. The ANOVA corroborates that gender is a consistently significant predictor. Students in the content-reinforcement labs outperform students in the experimentation labs on midterm II $(4.19 \pm 2.01$ in addition to the overall lab effect of $0.98 \pm 2.27)$. The mixed model ANOVA (see Table IV), however, finds no overall effects for lab conditions nor an overall interaction between conditions and exam.

To visualize the data, Fig. 2 shows the pairwise comparisons by the predictors included in the linear mixed models. The pairwise comparisons do not simultaneously account for the three predictors for exam performance. The results of the linear mixed models explain the relative magnitude 
TABLE III. Mixed model analysis of students' exam performance generated by the lme4 package [48] in R [49]. All exams are scored out of 100. Students who do not have scores for all exams are removed from the analysis; there are 95 participants in this analysis. The reference group is exam (final), major (nonphysics), gender (men), and lab condition (experimentation). Though $p$ values and $R^{2}$ are ill defined for mixed models, we report estimates. Statistical significance is calculated by the lmerTest package [50], and marginal and conditional $R^{2}$ are calculated using the MuMIn package [51].

\begin{tabular}{|c|c|c|}
\hline Effects & Model 1 & Model 2 \\
\hline (Intercept) & $70.92(1.86)^{* * *}$ & $71.83(1.97)^{\text {**** }}$ \\
\hline Major (physics) & $3.18(1.94)$ & $3.18(1.94)$ \\
\hline Gender (women) & $-6.68(2.45)^{* *}$ & $-6.68(2.45)^{* *}$ \\
\hline Lab condition (content-reinforcement) & $2.60(1.94)$ & $0.98(2.27)$ \\
\hline Exam (midterm I) & $10.44(1.01)^{* * *}$ & $10.05(1.50)^{* * * *}$ \\
\hline Exam (midterm II) & $-0.73(1.01)$ & $-3.06(1.50)^{*}$ \\
\hline Lab condition (content-reinforcement):exam (midterm I) & $\ldots$ & $0.69(2.01)$ \\
\hline Lab condition (content-reinforcement):exam (midterm II) & $\cdots$ & $4.19(2.01)^{*}$ \\
\hline$R_{m}^{2}$ & 0.24 & 0.24 \\
\hline$R_{c}^{2}$ & 0.70 & 0.70 \\
\hline AIC & 2092.1 & 2091.2 \\
\hline BIC & 2121.3 & 2127.7 \\
\hline Level-1 variance & 48.8 & 48.6 \\
\hline Level-2 variance & 70.7 & 74.6 \\
\hline$\chi_{\text {diff }}^{2}$ & \multicolumn{2}{|c|}{4.905} \\
\hline
\end{tabular}

of each predictor on students' exam performance while controlling for the other predictors.

From Fig. 2, we see that students' scores on midterm I are ceilinged and may hide an existing performance difference between students in each lab condition early in the semester. With the performance gap between lab conditions on midterm II, but the lack of a gap on the final exam, it is possible that an existing gap is closed during the semester. Many other factors may lead to the differences, so we are hesitant to attribute any potential explanations to the lab

TABLE IV. Type III analysis of variance table for the mixed model regression analyses for exam score (calculated using Satterthwaite's approximation) validate the regression analyses, finding no overall effect for lab conditions and no interaction with exams.

\begin{tabular}{|c|c|c|c|}
\hline & & Model 1 & Model 2 \\
\hline Effect & $d f$ & $F$ & $F$ \\
\hline Major & 1 & 2.69 & 2.69 \\
\hline Gender & 1 & $7.45^{* *}$ & $7.45^{* *}$ \\
\hline Lab condition & 1 & 1.80 & 1.80 \\
\hline Exam & 2 & $76.01^{* * *}$ & $78.31^{* * *}$ \\
\hline Lab condition:exam & 2 & $\cdots$ & 2.48 \\
\hline
\end{tabular}

conditions. Furthermore, the difference in students' scores between lab conditions on midterm II is approximately as big as the difference between physics and nonphysics majors on the same exam and smaller than the difference between men and women (as seen in Fig. 2). However, the difference between physics and nonphysics majors persists to the final exam, while the effect of lab conditions does not appear to. The difference between men and women appears on all three exams. Thus, the effect of lab conditions is practically and educationally insignificant compared to other variables.

Overall, these results support our predictions: Namely, we cannot establish a consistent impact from labs on exam performance, despite substantially different lab experiences. Even when the physics content is reinforced through hands-on activities in the content-reinforcement labs and nearly twice as many different physics concepts are demonstrated, there is no clear benefit for students' performance on exams across a full semester. Table XI in Appendix A 3 furthermore supports this conclusion by replicating the exam performance analysis in the subsequent course and, again, not finding distinguishable effects between lab conditions.

\section{Attitudes and beliefs about experimentation}

We evaluate students' attitudes and beliefs about experimental physics using the E-CLASS and the LES. From 

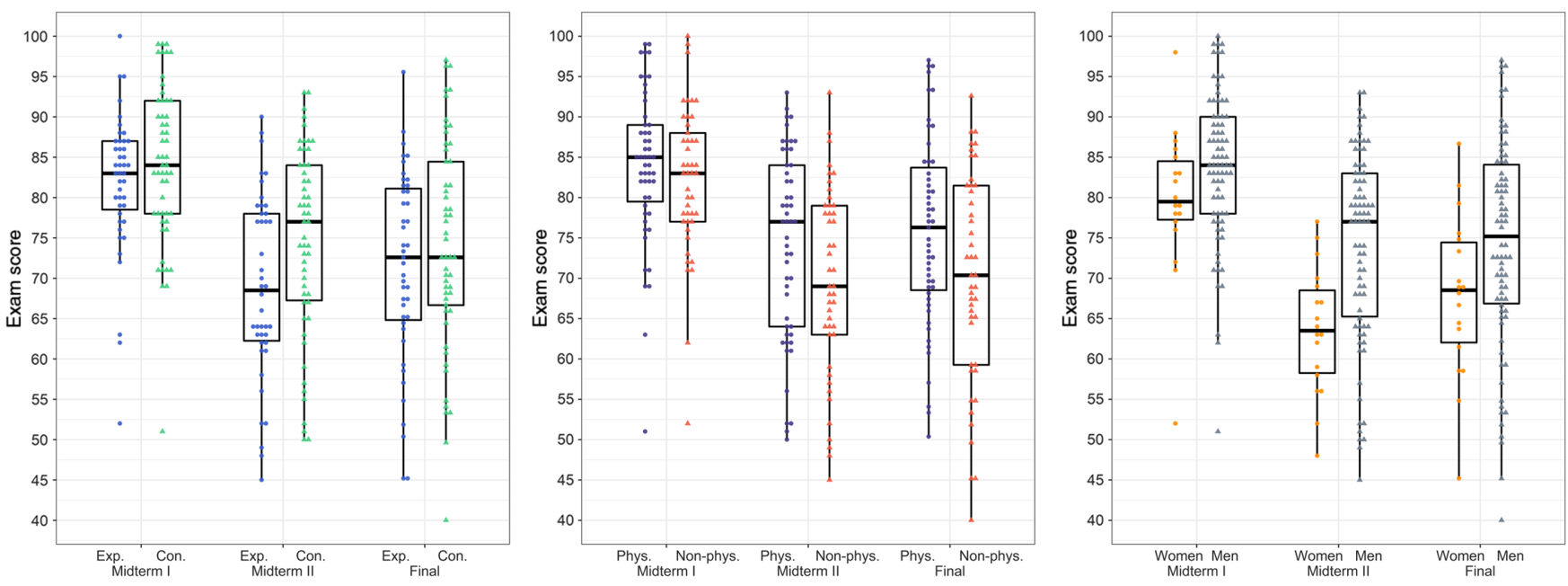

FIG. 2. Pairwise comparisons of exam scores by lab condition (left), major (center), and gender (right) for semester 1 show similar distributions between lab conditions, except on midterm II, but suggest different distributions between physics and nonphysics majors and between women and men on all exams. All exams are scored out of 100.

these analyses, we find that in the experimentation labs students' attitudes and beliefs about experimental physics improve when compared to those in the contentreinforcement labs. Students' responses to the LES also align with their experiences in the lab.

\section{E-CLASS}

Table V shows the results of the E-CLASS regressions. Models 2 and 3 in Table $V$ are statistically indistinguishable and explain the data better than model 1 (see model criteria in Table $\mathrm{V}$ and diagnostic plots in Fig. 4 in Appendix A 4 a). In models 2 and 3, lab condition strongly predicts students' E-CLASS postscores, more strongly than gender or major.
The gain for experimentation labs is especially influential for students who enter their lab with relatively low E-CLASS prescores. For example, if a nonphysics major man in the content-reinforcement labs scores 18 for his prescore (just below the median prescore), then his predicted postscore is $14.6 \pm 3.2$ (model 3, reported with $95 \%$ confidence interval). A nonphysics major woman in the content-reinforcement labs with a prescore of 18 has a predicted postscore of $16.4 \pm 3.9$. In the experimentation labs, the same students would have predicted postscores of $19.9 \pm 2.4$ and $21.7 \pm 3.3$, respectively. The interaction effects indicate that postscores are positively affected by the experimentation lab condition up to a prescore of about 21 , which is similar to the mean score of students who persist

TABLE V. Regression analysis of students' postscore on the E-CLASS using the STATS package in R [49]. Models 2 and 3 are statistically equivalent and fit the data better than model 1. There are 86 matched E-CLASS responses included in this analysis. $\chi_{\text {diff }}^{2}$ is calculated using the lmTest package [52] in R [49].

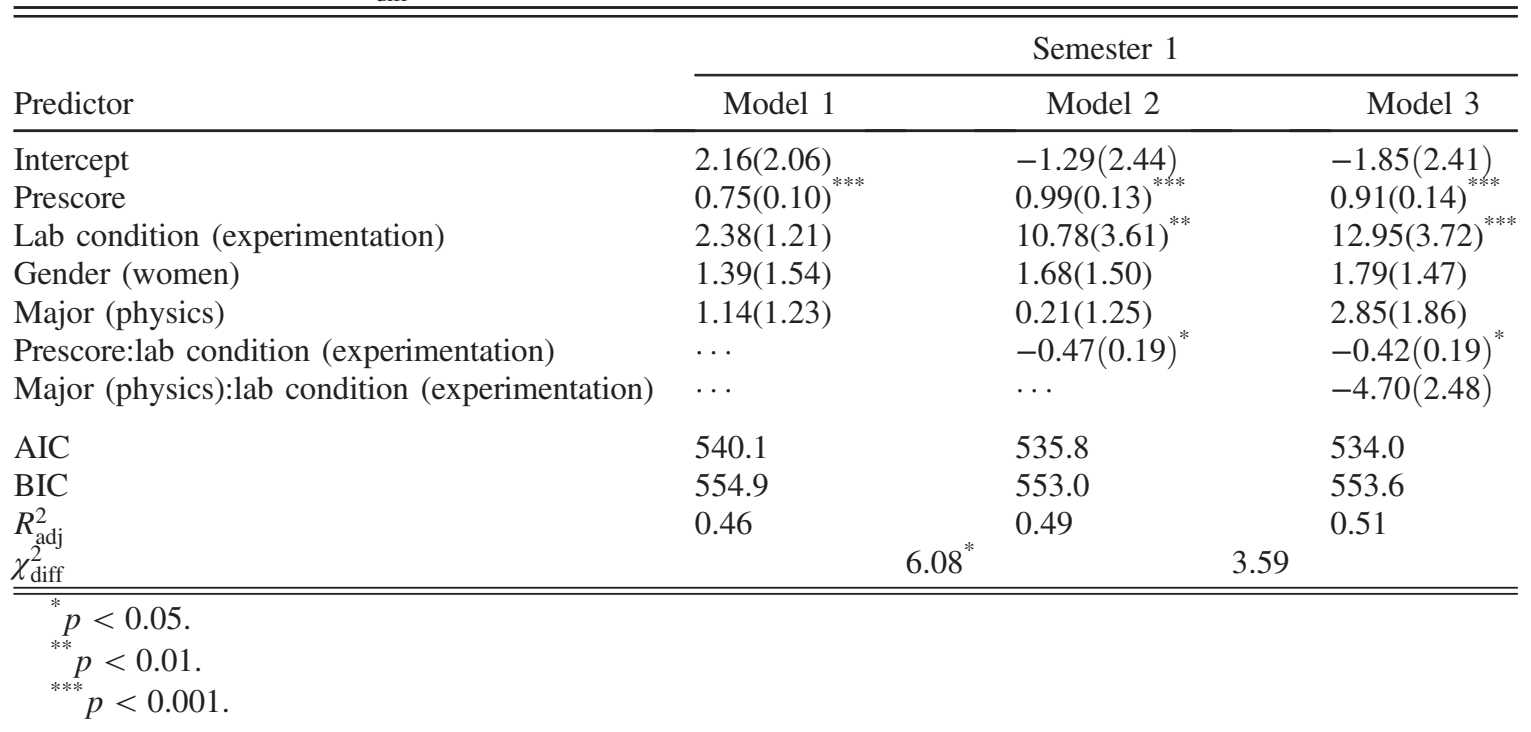



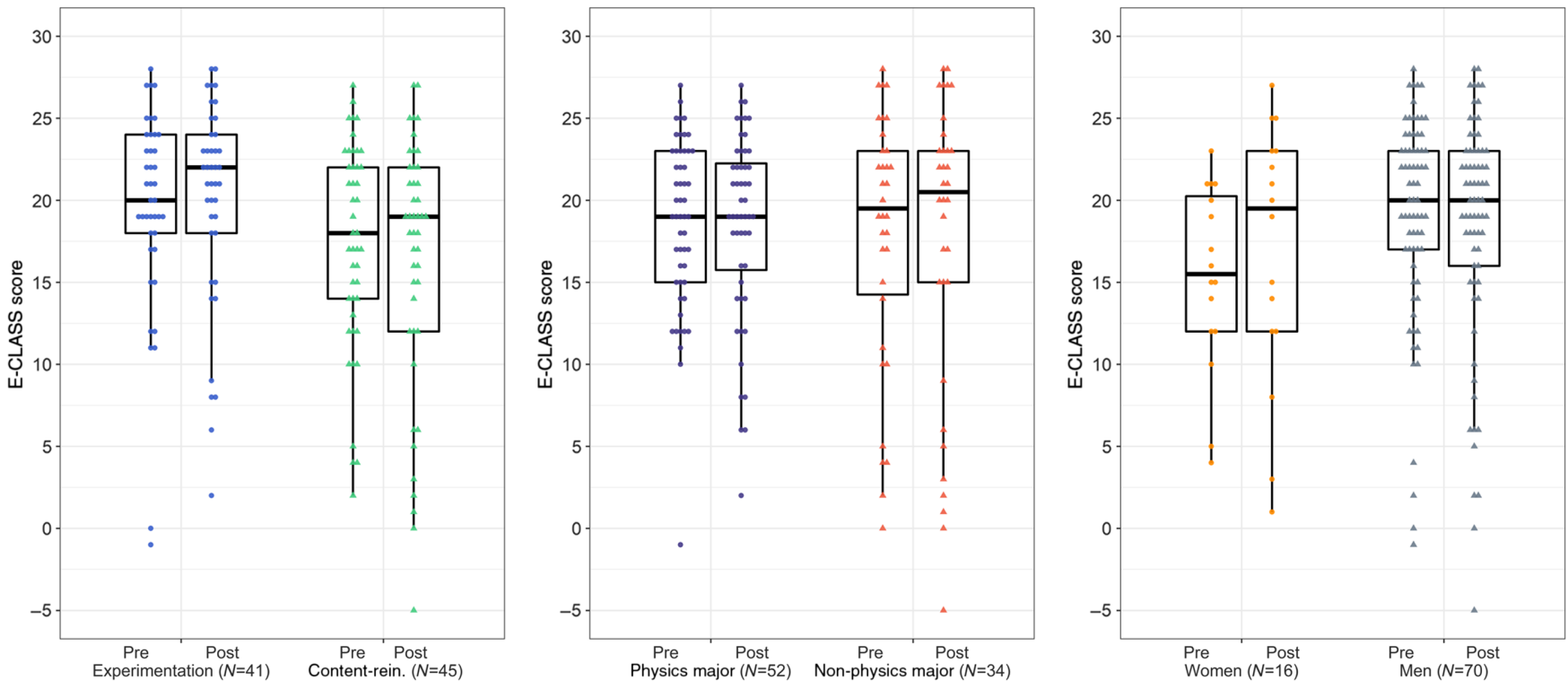

FIG. 3. E-CLASS scores by lab condition (left), major (center), and gender (right). These results should be interpreted along with Table V.

into upper-level physics labs [43]. For students who begin with lower E-CLASS prescores and are in contentreinforcement labs, their postscores tend to be negatively affected.

For students with higher E-CLASS prescores, their scores on the E-CLASS are ceilinged, which affects the degree to which improvements can be measured. As shown in Fig. 3, prescores of students in the experimentation labs are higher than the students in the content-reinforcement labs, and, therefore, the ceiling effect is stronger for students in the experimentation labs.

The analysis for testing stability into semesters 2 and 3 is given in Table XIV (Appendix B 2), and trends are similar between the experimentation lab cohorts. These results demonstrate that shifting lab instruction to teach experimentation positively and consistently affects students' attitudes and beliefs about experimental physics, particularly for students with lower E-CLASS prescores. Surprisingly, this study finds no differences in students' postscores based on major or gender, unlike previous work in first-year lab instruction [33].

\section{Lab epistemology survey}

Table VI shows the frequency of applied codes to students' responses. Students in the different lab conditions respond differently to questions about the purpose of lab activities (observed $\chi_{S}^{2}=20.75, p=0.004$ ) and the trustworthiness of experimental results (observed $\chi_{S}^{2}=22.56$, $p=0.001)$ but not the definitions of a scientific theory (observed $\chi_{S}^{2}=12.95, p=0.121$ ). Code-by-code comparisons reveal qualitative differences between responses separated by lab conditions.
For the question about the purpose of lab activities, more students' responses in the content-reinforcement labs include statements coded as "supplemental learning" (i.e., experiments facilitate learning of theory and/or concepts) than students' responses in the experimentation labs. Supplementing lecture is an explicit goal of the contentreinforcement labs and is explicitly not a goal in the experimentation labs. Furthermore, more students in the experimentation labs indicate additional goals such as "theory testing" and "scientific abilities," and they do so at frequencies higher than those reported for introductory calculus-based physics students in previous studies and around the frequency of upper-division students [35]. Because responses from students in content-reinforcement labs are consistent with prior results, the result in the experimentation labs suggests that the lab instruction, rather than the population of students, explains the differences from previous work.

Students in the experimentation labs also more frequently identify uncertainty evaluation as a way to know if a result is acceptable or trustworthy. Though both experimentation and content-reinforcement labs include introductions to measurement uncertainty, the experimentation labs regularly revisit and build on these topics. The emphasis in experimentation labs on using quantitative comparisons to inform experimentation decisions is also evident through students' responses about statistical analyses. We suspect that higher frequencies of "high-quality procedure or method" by students in the content-reinforcement labs occurs because students carefully follow lab instructions provided by the instructor (implying high quality).

Formal definitions of scientific theories are not explicitly taught in either lab condition. Therefore, it is unsurprising 
TABLE VI. An analysis of LES responses finds that students' explanations for why experiments are part of physics courses and their criteria for trustworthy experimental results differ across lab conditions. Multiple codes may apply to a response, so totals exceed $100 \%$. Vague responses are removed from the analysis, accounting for differing numbers of responses by question. Hu and Zwickl's results are next to the corresponding code(s); we split two of their original codes into two separate codes.

\begin{tabular}{|c|c|c|c|c|c|c|}
\hline \multirow[b]{2}{*}{ Question } & \multirow[b]{2}{*}{ Code } & \multicolumn{2}{|c|}{ Semester 1} & \multicolumn{3}{|c|}{$\mathrm{Hu}$ and Zwickl $[35,36]$} \\
\hline & & Exp. & Con. & Intro. calc. & Upper & Ph.D. \\
\hline \multirow{8}{*}{$\begin{array}{l}\text { In your opinion, why are experiments } \\
\text { a common part of physics courses? }\end{array}$} & & $N=29$ & $N=44$ & $N=28$ & $N=20$ & $N=31$ \\
\hline & Supplemental learning & $66 \%$ & $84 \%$ & $100 \%$ & $70 \%$ & $55 \%$ \\
\hline & Theory testing & $28 \%$ & $7 \%$ & $21 \%$ & $55 \%$ & $42 \%$ \\
\hline & Theory confirming & $28 \%$ & $18 \%$ & & & \\
\hline & Empirical nature & $17 \%$ & $5 \%$ & $7 \%$ & $20 \%$ & $74 \%$ \\
\hline & Scientific abilities & $21 \%$ & $5 \%$ & $11 \%$ & $30 \%$ & $35 \%$ \\
\hline & Science appreciation & $14 \%$ & $5 \%$ & $4 \%$ & $10 \%$ & $32 \%$ \\
\hline & Career or research preparation & $3 \%$ & $9 \%$ & $4 \%$ & $20 \%$ & $26 \%$ \\
\hline \multirow{6}{*}{$\begin{array}{l}\text { In your opinion, what defines } \\
\text { a scientific theory? }\end{array}$} & & $N=30$ & $N=42$ & $N=28$ & $N=20$ & $N=31$ \\
\hline & Explanatory or predictive power & $50 \%$ & $45 \%$ & $43 \%$ & $70 \%$ & $84 \%$ \\
\hline & Supported by existing evidence & $60 \%$ & $43 \%$ & $68 \%$ & $75 \%$ & $45 \%$ \\
\hline & Proven (unspecified how) & $10 \%$ & $2 \%$ & $\ldots$ & $\ldots$ & $\ldots$ \\
\hline & Expressed quantitatively & $33 \%$ & $17 \%$ & $4 \%$ & $30 \%$ & $29 \%$ \\
\hline & Falsifiable or testable & $17 \%$ & $31 \%$ & $\cdots$ & $\cdots$ & $\cdots$ \\
\hline \multirow{8}{*}{$\begin{array}{l}\text { How do you know if an experimental } \\
\text { result is acceptable or trustworthy? }\end{array}$} & & $N=30$ & $N=43$ & $N=28$ & $N=20$ & $N=31$ \\
\hline & Comparing to theory & $17 \%$ & $23 \%$ & $68 \%$ & $35 \%$ & $50 \%$ \\
\hline & Comparing to other people & $17 \%$ & $19 \%$ & $29 \%$ & $80 \%$ & $35 \%$ \\
\hline & Repeatability & $53 \%$ & $53 \%$ & $39 \%$ & $25 \%$ & $71 \%$ \\
\hline & Uncertainty evaluation & $50 \%$ & $19 \%$ & $25 \%$ & $55 \%$ & $32 \%$ \\
\hline & Statistical analyses & $47 \%$ & $12 \%$ & & & \\
\hline & High-quality procedure or method & $33 \%$ & $49 \%$ & $11 \%$ & $5 \%$ & $39 \%$ \\
\hline & Authority figures & $0 \%$ & $0 \%$ & $7 \%$ & $0 \%$ & $0 \%$ \\
\hline
\end{tabular}

that there are no overall differences in students' responses between lab conditions. However, some individual codes appear at different frequencies between conditions such as "supported by existing evidence" and "falsifiable or testable." The former (stated by more students in the experimentation labs) requires students to state that evidence already exists to support the theory, while the latter (stated by more students in the content-reinforcement labs) does not require existing evidence, only that evidence can be obtained. That is, the "supported by existing evidence" code includes the notion of falsifiable or testable, in that a theory has to have already been tested such that there is supporting evidence. Students in the experimentation labs engage in activities where they may uncover disagreements between data and a model (Sec. IVA 2), and so they may view supportive evidence as an essential component of a scientific theory. In contrast, students in the content-reinforcement labs rarely have opportunities to explore these disagreements.

\section{DISCUSSION}

This study is the first to isolate and directly measure the effects of different instructional goals for lab courses on student outcomes and demonstrate sustained improvement after the initial implementation. We have three main findings from the study. First, our analysis of students' exam performance corroborates prior work that claims traditional labs do not provide measurable added value to learning course content [6,7]. We extend this work to test the impact of experimentation labs compared with content-reinforcement labs on students' learning of the physics content knowledge. Our results cannot distinguish exam scores between lab conditions, even though the number of physics topics explored is cut in half in the experimentation labs.

Second, the research also directly demonstrates that experimentation labs better engage students, in terms of both quantity and quality of engagement, with experimentation. This demonstration serves to validate that the intent of the experimentation labs is enacted through the instruction. Students in the experimentation labs are much more likely to iterate to improve their methods (with or without prompting) and to identify and interpret disagreements between their data and a given model. These behaviors are almost entirely unseen in the content-reinforcement labs, even on an item with explicit prompting. Additionally, the differences between students' responses on the LES suggest that engagement in lab activities shifts students' beliefs about the nature of experimental physics. These results demonstrate a significant educational benefit to engaging students in experimentation during their labs. 
Third, the study directly demonstrates that, for students who enter with E-CLASS prescores below that of students who persist into upper-division physics courses [43], experimentation labs improve students' attitudes about and perceptions of experimental physics, while contentreinforcement labs negatively affect these measures. Those students with relatively low prescores most benefit from participation in the experimentation labs and are most negatively impacted by the content-reinforcement labs. Although we do not observe a statistically significant difference in men's and women's performance on the E-CLASS, our results indicate that women enter the lab with lower prescores than men. If lab instruction impacts students with lower prescores, then it is possible that lab instruction will directly impact the attitudes and beliefs of women and possibly other underrepresented minority students. Future work should further test this possibility.

This study is novel in that the students represent a unique population in the physics education research literature [44], in that many of the students intend to major in physics or are interested in pursuing research in physics-related fields. This novelty also serves as a limitation: Some of our measures are not well calibrated for this population (which may also be due to the selective institution studied). Based on the data, the course exams and measures of lab engagement are appropriate, but the code book for the LES has to be modified from previous work to adapt to students' responses. On the E-CLASS, many students enter with relatively high prescores, which may be atypical in most introductory physics courses. Restricting the sample to students in a single course at a single selective institution is also both a limitation and an affordance; the narrow sample facilitates a controlled study but presents a need for testing in other courses at other institutions. We look forward to replication studies at other institutions with varied populations and approaches to lab instruction that aim to teach experimentation to determine the extent to which these results may (or may not) be generalized.

Our demonstration of students' engagement in experimentation is also limited by the data sources used. Based on video observations of groups in the experimentation labs, we suspect that several groups underreported their engagement in experimentation behaviors through their lab notes. Observations of groups in the content-reinforcement labs suggest that often one or two group members would dictate responses to other group members rather than individually or collaboratively developing responses. Future work should involve structured observations to compare students' actual behaviors in labs to the behaviors that they record. We also recommend evaluating the effectiveness of such lab instruction for teaching other types of experimentation skills, such as students' communication skills or abilities to analyze and visualize data.

Our analyses raise several questions about the relative sizes of the effects of lab conditions, major, and gender on the measures that we investigate. For example, prior research on the E-CLASS identifies differences in performance between men and women in first-year lab instruction [33]. Our study, however, finds no significant difference when controlling for prescore, lab conditions, and major. Future work should aim to disentangle the relative effects of different forms of lab instruction and other variables on performance.

\section{CONCLUSIONS}

With the ongoing push to shift lab instruction to engage students in the scientific process, this study suggests that the shift is possible without detriment to students' exam performance and with many added benefits. Removing much of the physics content from the lab to, instead, teach experimentation engages students in expertlike behaviors and improves their attitudes and beliefs about experimental physics, with no measurable cost to their physics content knowledge.

Departments and instructors should identify the instructional goals and role of labs in their introductory physics courses and recognize the opportunities to teach skills that are unique to labs without pressure to cover physics content. The American Association of Physics Teachers has developed recommendations for learning goals for undergraduate physics labs [2], and Ref. [39] presents examples of using those learning goals to inform the development of lab activities. In addition to the lab curriculum presented in this paper (up-to-date versions are found in Ref. [41]), several curricula and activities exist that engage students in different aspects of the experimentation process such as those found in Refs. [45-47].

\section{ACKNOWLEDGMENTS}

We thank Mark Lory-Moran for invaluable support in transforming the labs at Cornell, Dr. Michael Niemack, Jaron Kent-Dobias, and the Cornell Physics Lab Committee for assistance with modifying lab activities, Dr. Katherine Quinn, Dr. Kathryn McGill, and Michelle Kelley for conducting the lab observations used in our calculations of students' time spent in lab, Dr. Dehui $\mathrm{Hu}$ and Dr. Ben Zwickl for sharing their code book and discussions about the coding scheme for the lab epistemology survey, Dr. Shima Salehi for discussions about the analyses, and the Cornell Physics Education Research Lab for feedback on the manuscript. This work is supported in part by Cornell University's College of Arts and Sciences Active Learning Initiative and the President's Council for Cornell Women Affinito-Stewart grant program.

\section{APPENDIX A: METHODS}

\section{Participants and conditions}

In both conditions, students submit short prelab activities (about $10 \mathrm{~min}$ ) by the start of each lab period and submit 
TABLE VII. Descriptions of lab instructions to illustrate the differences in materials used in content-reinforcement and experimentation labs. Counts are reported with means and standard errors. Question count includes fill-in-theblanks questions and questions posed for students to consider as part of the instructions. Over 9 weeks, there are nine lab instruction packets for the content-reinforcement labs and five packets for the experimentation labs; the counts are averaged by lab instruction packet.

\begin{tabular}{|c|c|c|c|c|}
\hline \multirow[b]{3}{*}{$\underline{\text { Lab instructions }}$} & \multicolumn{2}{|c|}{ Semester 1} & \multirow{3}{*}{$\frac{\frac{\text { Semester } 2}{\text { Experimentation }}}{(N=5)}$} & \multirow{3}{*}{$\frac{\frac{\text { Semester } 3}{\text { Experimentation }}}{(N=5)}$} \\
\hline & Content-reinforcement & Experimentation & & \\
\hline & $(N=9)$ & $(N=5)$ & & \\
\hline Word count & $2300 \pm 300$ & $810 \pm 140$ & $760 \pm 130$ & $860 \pm 170$ \\
\hline Page count & $11.8 \pm 0.7$ & $3.8 \pm 0.7$ & $3.2 \pm 0.6$ & $3.4 \pm 0.5$ \\
\hline Questions & $25 \pm 4$ & $6 \pm 3$ & $6 \pm 2$ & $9 \pm 3$ \\
\hline Figures & $3.1 \pm 0.6$ & $0.2 \pm 0.2$ & $0.2 \pm 0.2$ & $0.2 \pm 0.2$ \\
\hline Equations & $5 \pm 2$ & $0.4 \pm 0.2$ & $0.4 \pm 0.2$ & $0.4 \pm 0.2$ \\
\hline Fill in the blanks & $27 \pm 2$ & 0 & 0 & 0 \\
\hline
\end{tabular}

their lab work by the end of the lab period. In the contentreinforcement labs, students turn in their lab manuals individually with all questions completed. In the experimentation labs, groups submit collaborative, electronic lab notes detailing their experimentation process and justifications for their decisions. In semester 1, the labs in both conditions were graded on a pass-fail basis, and students were evaluated on their active and on-task participation during lab activities and not the quality or correctness of their submitted work. In semesters 2 and 3 , students' lab notes were graded according to rubrics focused on the experimentation process and decision making, similar to the scientific abilities rubrics in an investigative science learning environment [13].

In the experimentation labs, there are only five lab activities across the 9 weeks of labs; four of the five labs are spread over 2 weeks. In the content-reinforcement labs, there is a new activity each week. Table VII summarizes the instructions given to students in each condition, with averages by lab activity (not by week); all prelab activities are excluded from these counts. The increased amount of structure in the content-reinforcement labs is evidenced through significantly more written information (words, pages, figures, and equations) and more questions.

Constraints of scheduling and resource allocation require some logistical differences between the lab conditions, as well. Because of room sizes for the labs, most students in the content-reinforcement labs worked in groups of four, while groups in the experimentation labs varied from two to four students. In semester 1 , four lab instructors teught five sections, so two sections of content-reinforcement labs had the same instructor. All four instructors were experienced teachers and regularly demonstrated commitment to their teaching assignment and engage students in the lab activities. None of the lab instructors are physics education researchers nor are developers of the lab materials. In semester 2, there were two lab instructors for two sections, and both instructors were less experienced than those in the previous semester.
One of the instructors was a new graduate student in the physics education research group. There were also two undergraduate teaching assistants, one in each section, who had been enrolled as students in the experimentation labs the previous semester. In semester 3, there were three lab instructors for five sections. One instructor previously taught in the experimentation labs, and the other two instructors had prior teaching experience but were new to these labs. Four sections had one or two undergraduate teaching assistants.

Table VIII shows the number of students included in each analysis in the main paper compared to the total number of responses received for that data source. We use the number of students who complete the final exam as a proxy for the number of students who complete the course. We estimate that there are about 96 students who completed the course and elected to participate in the study.

\section{Students' engagement with experimentation}

Because the measurements are made to the nearest 5-min interval, students' time in lab is slightly overestimated for both lab conditions. We first calculate the mean time per student in each lab section for each lab week in each condition. Then, we average over the lab sections to determine the mean time in lab for each lab week. Finally, we average over the lab weeks to determine the

TABLE VIII. Total number of students in each dataset in semester 1 before filtering for valid responses compared to the responses included in the analyses. Includes only students who consented to participate in the research.

\begin{tabular}{lcccccccc}
\hline \hline & \multicolumn{3}{c}{ Exams } & & \multicolumn{3}{c}{ E-CLASS } \\
\cline { 2 - 4 } \cline { 7 - 8 } & Midterm I & Midterm II & Final nne & Pre & Post & LES \\
\hline Total & 98 & 97 & 96 & & 104 & 95 & 74 \\
Included & 95 & 95 & 95 & & 86 & 86 & 74 \\
$\quad$ in analysis & & & & & & & \\
\hline \hline
\end{tabular}


TABLE IX. Mean time reported with standard errors in minutes for students to complete each lab used in the calculations of mean time in lab.

\begin{tabular}{|c|c|c|c|c|c|c|c|c|}
\hline \multirow[b]{2}{*}{ Week } & \multicolumn{4}{|c|}{ Experimentation } & \multicolumn{4}{|c|}{ Content-reinforcement } \\
\hline & Lab activity & Mean time & Students & Sections & Lab activity & Mean time & Students & Sections \\
\hline 2 & Pendulum II & $118 \pm 0$ & 22 & 1 & Dynamics of $1 \mathrm{D}$ motion & $105 \pm 2$ & 32 & 2 \\
\hline 4 & Terminal velocity II & $132 \pm 3$ & 44 & 2 & Force laws & $71 \pm 2$ & 53 & 3 \\
\hline 5 & Hooke's law I & $118 \pm 1$ & 42 & 2 & $\ldots$ & $\ldots$ & $\ldots$ & $\cdots$ \\
\hline 7 & Collisions & $113 \pm 0$ & 40 & 2 & Stick-together collisions & $99 \pm 2$ & 55 & 3 \\
\hline 9 & Project lab II & $108 \pm 3$ & 42 & 2 & Free and driven oscillations & $89 \pm 3$ & 49 & 3 \\
\hline
\end{tabular}

overall average time that students spend in lab. We use this method because there is greater variance across lab weeks (means ranging from 108 to $132 \mathrm{~min}$ in experimentation labs and 71 to $105 \mathrm{~min}$ in content-reinforcement labs) than within lab weeks (standard errors ranging from 0 to 3 min in experimentation labs and from 2 to 3 in contentreinforcement labs), and within-week variance is less than the instrumental precision afforded by the observation protocol (i.e., 5-min intervals).

Table IX includes mean time for lab activities for which there are observers in attendance.

\section{Exam performance}

We use regression analyses to compare performance on exam scores between conditions. We use prior literature to select the variables to include in our models. Gender is included as a binary, categorical predictor in our models; all students in this study self-identify as either men or women despite other options available on the surveys. As shown in Table II, the proportion of physics majors is the largest difference between the content-reinforcement and experimentation lab populations. Therefore, we treat major as a binary, categorical variable with options of physics major or nonphysics major. Several students' majors are unknown, and we choose to group unknown majors with nonphysics majors. We avoid splitting major into additional categories to maintain statistical power. We choose not to include race and ethnicity in our models due to the small and identifying number of students that self-identify as a member of an underrepresented racial or ethnic group in physics.

Using the lme4 package [48] in R [49], the models expressed in $\mathrm{R}$ syntax are

(1) Exam.Score $\sim$ Major + Lab.Condition + Exam

$$
+ \text { Gender }+(1 \mid \text { Student.ID }) \text {, }
$$

(2) Exam.Score $\sim$ Major + Lab.Condition $*$ Exam

$$
+ \text { Gender }+(1 \mid \text { Student.ID }) \text {. }
$$

Exam.Score is each students' score on each exam and is treated as a continuous variable. Exam is treated as a three-level categorical predictor (midterm I, midterm II, and final), and Major, Gender, and Lab.Condition are binary, categorical predictors, as defined earlier. Table $\mathrm{X}$ provides descriptive statistics for the exam scores separated by lab conditions for all participants in semester 1 .

Many students persisted into the introductory electricity and magnetism course that follows the introductory mechanics course in semester 1. The students' incoming lab experiences were mixed due to the lab conditions in the prior semester. Students, again, selected into either contentreinforcement or experimentation lab sections, independent of their experiences in semester 1 . Table XI shows the results of students' exam performance in this subsequent course. We again cannot distinguish performance differences between lab conditions. On midterm II, students in the experimentation labs slightly outperform students in the contentreinforcement labs, and the relative sizes of these differences are similar to those from the study in the main text. These results, in combination with those in Table III, support an interpretation that there is no measurable impact on students' exam performance due to their experiences in labs rather than an interpretation that lab experience has a small effect that is imprecisely measured in semester 1 .

\section{Attitudes and beliefs about experimental physics a. E-CLASS}

The models expressed using $\mathrm{R}$ syntax are

(1) Postscore $\sim$ Prescore + Lab.Condition + Gender + Major,

(2) Postscore $\sim$ Prescore $*$ Lab.Condition + Gender

(3) Postscore $\sim$ Prescore $*$ Lab.Condition + Gender + Major $*$ Lab.Condition.

Figure 4 shows diagnostic plots to demonstrate the appropriateness of the model fits to the data.

We also perform a forward stepwise regression to test whether other models explained the data significantly better than the models selected from prior literature. In this process, we begin by testing each predictor separately 
TABLE X. Mean and median exam scores by lab condition for all students' scores in semester 1. Mean scores are reported with standard deviations.

\begin{tabular}{lll}
\hline \hline Exam & \multicolumn{1}{c}{ Content-reinforcement } & Experimentation \\
\hline Midterm I & Mean $84 \pm 10 \%(N=55)$ & $82 \pm 9 \%(N=43)$ \\
& Median $85 \%$ & $84 \%$ \\
\multirow{2}{*}{ Midterm II Mean $74 \pm 12 \%(N=55)$} & $69 \pm 11 \%(N=42)$ \\
& Median $76 \%$ & $68 \%$ \\
Final & Mean $74 \pm 13 \%(N=53)$ & $72 \pm 12 \%(N=43)$ \\
& Median 73\% & $73 \%$ \\
\hline \hline
\end{tabular}

and keep the strongest predictor in all subsequent models. We continue this process until we determine models with the lowest Akaike information criterion (AIC) and Bayesian information criterion (BIC). We view this process as a confirmatory step to demonstrate that the models we select based on prior studies are similar to the best-fitting models of the local situation. All models converge on the same conclusions, and so we present the analyses of the three models above in the results.

Table XII includes a selection of models tested in the forward stepwise regression performed on E-CLASS data from students from semester 1. Table XIII details descriptive statistics for the three semesters that the E-CLASS is administered in the course including for both the full dataset and the subset used in the main text analyses.

\section{b. Lab epistemology survey}

Because of our modifications of Hu and Zwickl's LES code book, we provide the definitions of the codes that we apply in this study. Redundancy in lettering guides the reader to understand how codes collapse into the codes assigned by $\mathrm{Hu}$ and Zwickl [35,36]. There are some modifications of the names for some codes; for clarification, we include reference to the original names.

Question 1: In your opinion, why are experiments a common part of physics courses?

(A) Supplemental learning.-Experiments facilitate learning of theory and/or concepts.

(B1) Theory testing.-Experiments provide opportunities to test theories.

(B2) Theory confirming.-Experiments provide opportunities to confirm or prove theories.

(C) Empirical nature.-Physics theories, concepts, and/or laws are grounded in experiments and/or observations. Similarly, experiments are the historic approach to investigating nature and developing knowledge. Note: Reference [35] refers to this code as "foundation of physics".

(D) Scientific abilities.- Through experimentation, students acquire knowledge of scientific processes and/or practices and/or develop scientific abilities and/or skills.

(E) Science appreciation.-Through experimentation, students acquire knowledge of how science is carried out and/or how scientists study the world.

TABLE XI. Mixed model analysis of students' exam performance in the subsequent introductory electricity and magnetism course that immediately follows semester 1 . All exams are scored out of 100. Students who do not have scores for all exams are removed from the analysis. There are 65 participants in this analysis. The reference group is exam (final), major (nonphysics), gender (men), and lab condition (experimentation). We use the same models and packages to perform the analysis as those in Table III.

\begin{tabular}{lcc}
\hline \hline Effects & Model 1 & Model 2 \\
\hline (Intercept) & $62.19(2.90)^{* * *}$ & $62.02(3.09)^{* * *}$ \\
Major (physics) & $0.79(2.76)$ & $0.78(2.76)$ \\
Gender (women) & $-8.44(4.61)$ & $-8.07(4.60)$ \\
Lab condition (content-reinforcement) & $-0.69(2.71)$ & $-0.42(3.45)$ \\
Exam (midterm I) & $-3.58(1.88)$ & $-5.52(2.67)^{*}$ \\
Exam (midterm II) & $16.29(1.88)^{* * *}$ & $18.61(2.67)^{* * *}$ \\
Lab condition (content-reinforcement):exam (midterm I) & $\ldots$ & $3.72(3.69)$ \\
Lab condition (content-reinforcement):exam (midterm II) & $\ldots$ & $-4.44(3.69)$ \\
$R_{m}^{2}$ & 0.29 & 0.30 \\
$R_{c}^{2}$ & 0.58 & 0.60 \\
AIC & 1566.7 & 1565.9 \\
BIC & 1592.8 & 1598.6 \\
Level-1 variance & 114.7 & 110.5 \\
Level-2 variance & 78.6 & 80.0 \\
$\chi_{\text {diff }}^{2}$ & & \\
\hline \hline${ }_{*}^{*}<0.05$. & & \\
${ }_{*}^{* * * *} p<0.01$. & &
\end{tabular}


TABLE XII. A selection of models from a forward stepwise regression performed on the E-CLASS data from semester 1 that includes prescore, lab condition, gender, major, and all interactions to predict the postscore. Bold indicates the lowest values for model criteria.

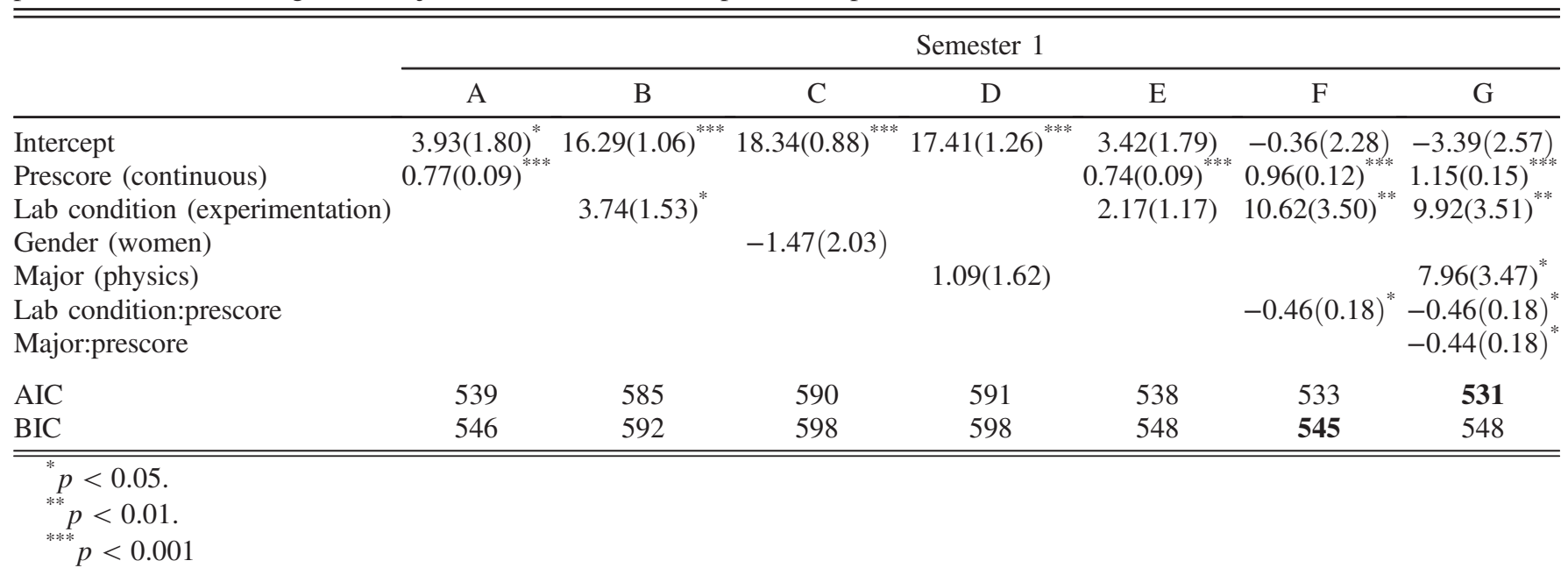

(F) Career or research preparation.-Experiments provide training for future jobs, careers, and/or research.

Question 3: In your opinion, what defines a scientific theory?

(A) Explanatory or predictive power-A scientific theory is used to understand, explain, and/or describe a phenomenon, how the world works, and/or why something happens. Alternatively, a scientific theory can be used to predict unknowns such as the behavior of a system or the results of an experiment.

(B) Supported by existing evidence.-A scientific theory must be tested, verified, and/or supported by evidence that consists of observations, collected facts, and/or experiments. Evidence exists that supports the theory. Note: We adapt the "evidence supported" code in Ref. [35] to include only existing evidence. Falsifiability or testable captures references to "can" and "could" be supported by evidence.
(C) Proven (unspecified how).-A scientific theory has proof or has been proven but the characteristic of the proof is vague (i.e., evidence or mathematics is missing from the description of the proof). Note: We add this code to include responses that are ambiguous as to how theories are proven.

(D) Expressed quantitatively.-A scientific theory is expressed quantitatively, usually or typically through a mathematical or other quantitative representation. Note: Reference [35] refers to this code as "quantitative aspect".

(E) Falsifiability or testable.-A scientific theory is falsifiable; there is a possibility of testing and/or observing evidence that demonstrates the theory does not hold. Language such as "could be" or "can be" when a response includes ideas around testing can indicate ideas of falsifiability that are included in this code. A scientific theory is testable even if evidence does not currently exist.

TABLE XIII. Descriptive statistics of all students' scores and of the subset of students' scores that are included in the E-CLASS analyses before and after lab instruction. Means are reported with standard deviations, and medians are reported with median absolute deviations.

\begin{tabular}{|c|c|c|c|c|c|c|}
\hline & & \multicolumn{2}{|c|}{ All scores } & & \multicolumn{2}{|c|}{ Included in analyses } \\
\hline & & Mean & Median & & Mean & Median \\
\hline Experimentation (S1) & $\begin{array}{l}\text { Pre }(N=46) \\
\text { Post }(N=43)\end{array}$ & $\begin{array}{l}19.4 \pm 6.3 \\
19.7 \pm 6.5\end{array}$ & $\begin{array}{l}20.5 \pm 3.0 \\
22.0 \pm 3.0\end{array}$ & $\begin{array}{l}\text { Pre }(N=41) \\
\text { Post }(N=41)\end{array}$ & $\begin{array}{l}19.4 \pm 6.3 \\
20.0 \pm 6.2\end{array}$ & $\begin{array}{l}20.0 \pm 3.0 \\
22.0 \pm 3.0\end{array}$ \\
\hline Content-reinforcement (S1) & $\begin{array}{l}\text { Pre }(N=58) \\
\text { Post }(N=52)\end{array}$ & $\begin{array}{l}17.1 \pm 6.5 \\
16.4 \pm 7.9\end{array}$ & $\begin{array}{l}17.5 \pm 4.5 \\
19.0 \pm 4.0\end{array}$ & $\begin{array}{l}\text { Pre }(N=45) \\
\text { Post }(N=45)\end{array}$ & $\begin{array}{l}17.3 \pm 6.3 \\
16.3 \pm 7.8\end{array}$ & $\begin{array}{l}18.0 \pm 4.0 \\
19.0 \pm 4.0\end{array}$ \\
\hline Experimentation (S2) & $\begin{array}{l}\text { Pre }(N=45) \\
\text { Post }(N=33)\end{array}$ & $\begin{array}{l}19.1 \pm 6.4 \\
20.6 \pm 6.9\end{array}$ & $\begin{array}{l}20.0 \pm 3.0 \\
23.0 \pm 3.0\end{array}$ & $\begin{array}{l}\text { Pre }(N=33) \\
\text { Post }(N=33)\end{array}$ & $\begin{array}{l}19.6 \pm 6.2 \\
20.6 \pm 6.6\end{array}$ & $\begin{array}{l}21.0 \pm 3.0 \\
23.0 \pm 3.0\end{array}$ \\
\hline Experimentation (S3) & $\begin{array}{l}\text { Pre }(N=96) \\
\text { Post }(N=81)\end{array}$ & $\begin{array}{l}19.6 \pm 5.5 \\
19.2 \pm 5.9\end{array}$ & $\begin{array}{l}21.0 \pm 3.5 \\
20.0 \pm 3.0\end{array}$ & $\begin{array}{l}\text { Pre }(N=73) \\
\text { Post }(N=73)\end{array}$ & $\begin{array}{l}19.5 \pm 5.5 \\
19.7 \pm 5.0\end{array}$ & $\begin{array}{l}21.0 \pm 3.0 \\
20.0 \pm 2.0\end{array}$ \\
\hline
\end{tabular}


Question 5: How do you know if an experimental result is acceptable or trustworthy? What gives you confidence that your data are trustworthy?

(A1) Comparing to theory.-If the experimental result matches with a theory and/or an expected value, then the result is trustworthy. Match may be indicated with words or phrases such as "close to," "similar," "identical to," etc.

(A2) Comparing to a "true" value.-If the experimental result matches with a true value or "right" answer, then the result is trustworthy. Note: Although no students' responses are coded as this, we decide
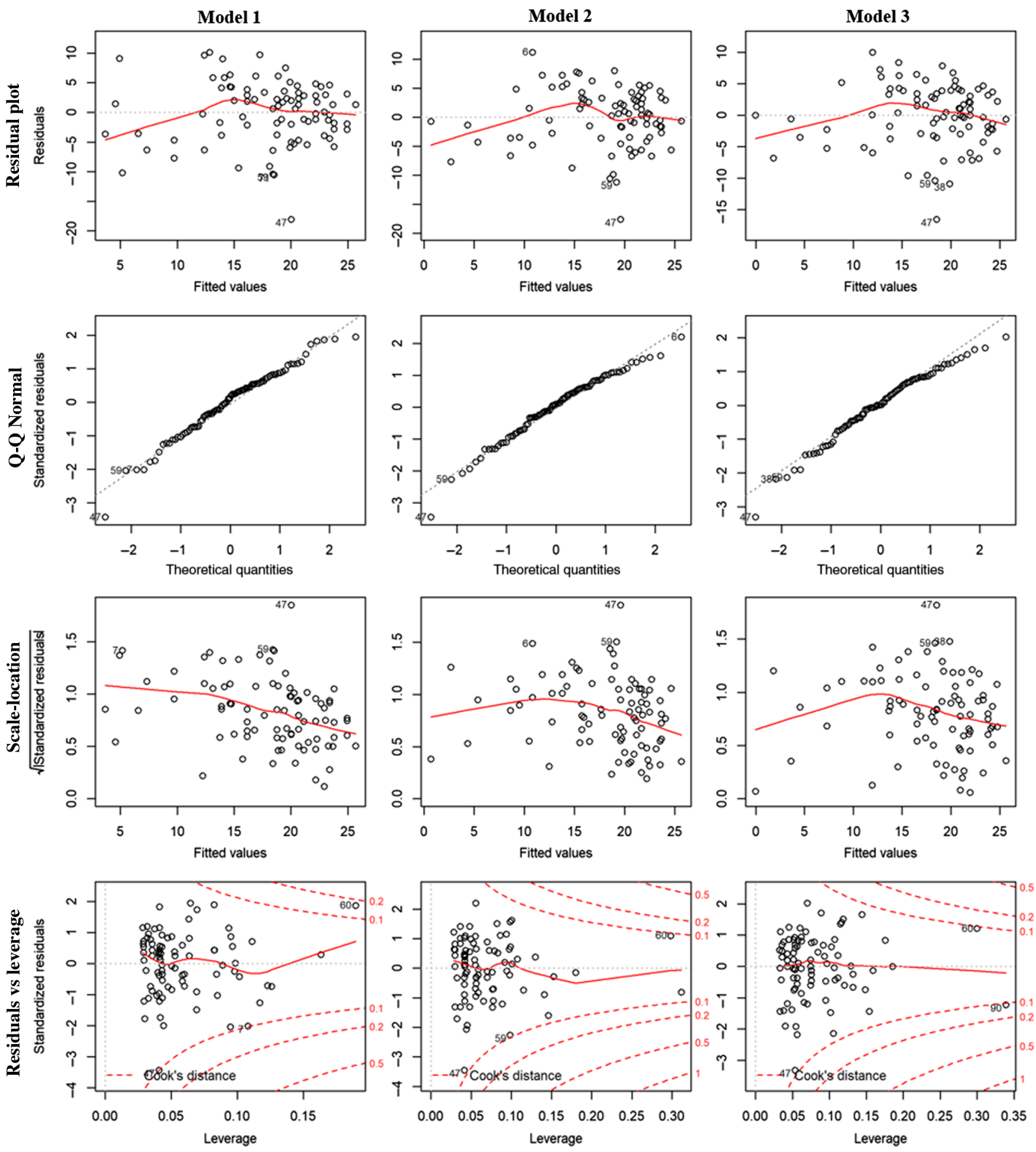

FIG. 4. Model diagnostic plots using E-CLASS scores of students in semester 1. 
separating theory from a definitively true value to be important for distinguishing between the characteristics of students' responses.

(B) Comparing to other people.-Experimental results are trustworthy when they are similar to published results or results from other people who are conducting similar or identical experiments.

(C) Repeatability.-Experimental results are trustworthy when the same person or group conducts the same experiment multiple times and finds consistent results. More generally, the results are reproducible without reference to other scientists.

(D1) Uncertainty evaluation.-The trustworthiness of results is justified through uncertainty evaluation.

(D2) Statistical analyses.-The trustworthiness of results is determined through statistical analyses. Note: We add this code to differentiate evaluating uncertainty from performing statistical analyses, because both are frequently described by students.

(E) High-quality procedure or methods.-Experimental results are trustworthy when the experimenter is confident in their methodology, procedure, and/or carefully documents their work. Examples include conducting experiments carefully, making sure everything is working well, confidence in procedure, checking whether mistakes have been made, understanding how equipment works, etc. Note: Reference [36] refers to this code as "quality work".
(F) Authority figures.-The trustworthiness of results is determined when an instructor confirms that results are trustworthy.

We use a nonparametric bootstrap procedure [53] to test the null hypothesis that codes are independent of lab conditions rather than a $\chi^{2}$ test of independence, because codes are not mutually exclusive (i.e., multiple codes could apply to a student's response). The students' responses and lab condition are independently resampled with replacement from the dataset 2000 times, and the test statistic is calculated for each replicate to build a sampling distribution for the modified chi-square statistic, $\chi_{S}^{2}$ [53]. The $p$ value is calculated using the fraction of replicate modified chi-square statistics that are at least as great as the observed $\chi_{S}^{2}$. We report results for the subset of codes that are published in Refs. $[35,36]$ and for codes that we add to adapt to students' responses. There are several codes with relatively few responses, and so these codes are omitted from the results.

\section{APPENDIX B: ADDITIONAL DISCUSSION OF RESULTS}

\section{Experimentation behaviors}

The variability between weeks likely results from the structure of the various lab activities. For example, in the second week of pendulum (pend. II), students are explicitly prompted to make changes to their experiment

TABLE XIV. Regressions performed on the outcome of postscore on the E-CLASS including semester 1 (S1), semester 2 (S2), and semester 3 (S3). The base comparison is lab condition (content-reinforcement S1), gender (men), and major (nonphysics). Statistical comparisons demonstrate that models 2 and 3 are statistically equivalent and better fits to the data than model 1 . There are 191 matched E-CLASS responses included in this analysis.

\begin{tabular}{|c|c|c|c|}
\hline Predictor & Model 1 & Model 2 & Model 3 \\
\hline Intercept & $4.85(1.38)^{* * *}$ & $0.22(2.04)$ & $-0.44(2.05)$ \\
\hline Prescore & $0.71(0.06)^{* * *}$ & $1.00(0.11)^{* * *}$ & $0.90(0.12)^{\text {**** }}$ \\
\hline Lab condition (experimentation $\mathrm{S} 1$ ) & $2.20(1.03)^{*}$ & $11.20(3.11)^{* * *}$ & $12.80(3.29)^{* * *}$ \\
\hline Lab condition (experimentation S2) & $2.54(1.09)^{*}$ & $6.35(3.36)$ & $7.53(3.45)^{*}$ \\
\hline Lab condition (experimentation S3) & $1.66(0.91)$ & $8.89(2.85)^{* *}$ & $9.90(2.97)^{* *}$ \\
\hline Gender (women) & $0.90(0.78)$ & $0.97(0.77)$ & $0.95(0.77)$ \\
\hline Major (physics) & $-0.13(0.72)$ & $-0.66(0.72)$ & $2.79(1.64)$ \\
\hline Prescore:lab condition (experimentation S1) & $\ldots$ & $-0.50(0.16)^{* *}$ & $-0.42(0.17)^{*}$ \\
\hline Prescore:lab condition (experimentation S2) & $\cdots$ & $-0.23(0.17)$ & $-0.13(0.18)$ \\
\hline Prescore:lab condition (experimentation S3) & $\ldots$ & $-0.41(0.15)^{* *}$ & $-0.31(0.15)^{*}$ \\
\hline Major (physics):lab condition (experimentation S1) & $\cdots$ & $\ldots$ & $-4.64(2.19)^{*}$ \\
\hline Major (physics):lab condition (experimentation S2) & $\cdots$ & $\cdots$ & $-4.44(2.29)$ \\
\hline Major (physics):lab condition (experimentation S3) & $\cdots$ & $\cdots$ & $-3.87(2.00)$ \\
\hline AIC & 1145 & 1140 & 1140 \\
\hline $\mathrm{BIC}$ & 1171 & 1175 & 1185 \\
\hline$R_{\text {adj }}^{2}$ & 0.47 & 0.50 & 0.50 \\
\hline$\chi_{\text {diff }}^{2}$ & & $11.48^{* *}$ & \\
\hline
\end{tabular}


to improve their measurements, and, therefore, it is unsurprising that nearly all groups do so in both semesters. Similar results are obtained for this activity in prior publications [40]. In contrast, for project lab II (proj. II), students develop their own research questions based on prior investigations, and there is very little structure or prompting as to whether to iterate to improve their experiments. Therefore, students' decisions depend on their chosen research question, as does the feasibility of iterating within a single lab period and identifying a disagreement with the model they are testing.

The variability between semesters likely results from the specific instructions provided by the different instructors. For example, in semester 1 the instructors used most of the first week of terminal velocity (TV I) to engage students in an activity on weighted least squares fitting. In semester 2, the instructors were asked to limit the activity to $45 \mathrm{~min}$, and so the students had more time to begin their experiments, allowing increased time for students to iterate on their methods. As a second example, students' investigations in project lab (proj. II) are driven by their group's research questions. In semester 1, the instructors provided little structure and allowed students ample time to develop a feasible project without assistance. Additionally, in one section, an event in the parking lot that was visible from the lab room distracted students during the final session [54]. In semester 2, the instructors were encouraged to check in with groups about the feasibility of their research question within the first half hour of the lab. We suspect these discussions help students narrow their investigation, giving them time to propose and carry out changes to their experiment.

\section{Attitudes and beliefs about experimental physics: E-CLASS}

To test the stability of the E-CLASS results, we run the same regression analyses across all three semesters. Table XIV shows the results of the regressions treating the lab condition as a four-level categorical variable to account for the differences between the labs each semester (semester 1 content-reinforcement, semester 1 experimentation, semester 2 experimentation, and semester 3 experimentation). Trends are similar across the three semesters of experimentation labs, supporting the results from the controlled study in semester 1 .

[1] Discipline-Based Education Research: Understanding and Improving Learning in Undergraduate Science and Engineering, edited by S. R. Singer, N. R. Nielsen, and H. A. Schweingruber (National Academies Press, Washington, DC, 2012).

[2] AAPT Committee on Laboratories, AAPT Recommendations for the Undergraduate Physics Laboratory Curricu- lum (American Association of Physics Teachers, College Park, MD, 2015).

[3] Joint Task Force on Undergraduate Physics Programs, Phys21: Preparing Physics Students for 21st Century Careers (American Physical Society and American Association of Physics Teachers, College Park, MD, 2016).

[4] Next Generation Science Standards Lead States, Next Generation Science Standard: For States, By States (National Academies Press, Washington, DC, 2013).

[5] President's Council of Advisors on Science and Technology, Engage to Excel: Producing One Million Additional College Graduates with Degrees in Science, Technology, Engineering, and Mathematics (United States Office of Science and Technology Policy, Washington, DC, 2012).

[6] N. G. Holmes, J. Olsen, J. L. Thomas, and C. E. Wieman, Valued Added or Misattributed? A Multi-Institution Study on the Education Benefit for Labs Reinforcing Physics Content, Phys. Rev. Phys. Educ. Res. 13, 010129 (2017).

[7] C. E. Wieman and N. G. Holmes, Measuring the Impact of an Instructional Laboratory on the Learning of Introductory Physics, Am. J. Phys. 83, 972 (2015).

[8] N. G. Holmes, C. E. Wieman, and D. A. Bonn, Teaching Critical Thinking, Proc. Natl. Acad. Sci. U.S.A. 112, 11199 (2015).

[9] B. R. Wilcox and H. J. Lewandowski, Open-Ended versus Guided Laboratory Activities: Impact on Students' Beliefs about Experimental Physics, Phys. Rev. Phys. Educ. Res. 12, 020132 (2016).

[10] B. R. Wilcox and H. J. Lewandowski, Developing Skills versus Reinforcing Concepts in Physics Labs: Insight from a Survey of Students' Beliefs about Experimental Physics, Phys. Rev. Phys. Educ. Res. 13, 010108 (2017).

[11] A. C. Mills, What Are Physics Labs Good for Anyway? (to be published).

[12] E. Etkina and S. Murthy, Using Introductory Labs to Engage Students in Experimental Design, Am. J. Phys. 74, 979 (2006).

[13] E. Etkina, A. Van Heuvelen, S. White-Brahmia, D. T. Brookes, M. Gentile, S. Murthy, D. Rosengrant, and A. Warren, Scientific Abilities and Their Assessment, Phys. Rev. Phys. Educ. Res. 2, 020103 (2006).

[14] E. Etkina, A. Karelina, and M. Ruibal-Villasenor, How Long Does It Take? A Study of Student Acquisition of Scientific Abilities, Phys. Rev. Phys. Educ. Res. 4, 020108 (2008).

[15] E. Etkina, A. Karelina, M. Ruibal-Villasenor, D. Rosengrant, R. Jordan, and C. E. Hmelo-Silver, Design and Reflection Help Students Develop Scientific Abilities: Learning in Introductory Physics Laboratories, J. Learn. Sci. 19, 54 (2010).

[16] J. A. Schmidt, J. M. Rosenberg, and P. N. Beymer, A Person-in-Context Approach to Student Engagement in Science: Examining Learning Activities and Choice, J. Res. Sci. Teach. 55, 19 (2018).

[17] A. Karelina and E. Etkina, Acting Like a Physicist: Student Approach Study to Experimental Design, Phys. Rev. Phys. Educ. Res. 3, 020106 (2007).

[18] We use physics content to mean the canonical concepts and ideas and physics-specific body of knowledge, not the skills and practices of the discipline. 
[19] E. Etkina, A. Van Heuvelen, A. Karelina, M. RuibalVillasenor, and D. Rosengrant, Spending Time on Design: Does It Hurt Physics Learning? PERC Proceedings 2007, AIP Conf. Proc. 951, 88 (2007).

[20] A. Madsen, S. B. McKagan, and E. C. Sayre, Gender Gap on Concept Inventories in Physics: What Is Consistent, What Is Inconsistent, and What Factors Influence the Gap?, Phys. Rev. Phys. Educ. Res. 9, 020121 (2013).

[21] L. Kost, S. Pollock, and N. Finkelstein, Characterizing the Gender Gap in Introductory Physics, Phys. Rev. Phys. Educ. Res. 5, 010101 (2009).

[22] J. Docktor and K. Heller, Gender Differences in Both Force Concept Inventory and Introductory Physics Performance, AIP Conf. Proc. 1064, 15 (2008).

[23] S. Bates, R. Donnelly, C MacPhee, D. Sands, M. Birch, and N. R. Walet, Gender Differences in Conceptual Understanding of Newtonian Mechanics: A UK Cross-Institution Comparison, Eur. J. Phys. 34, 421 (2013).

[24] V. P. Coletta, J. A. Phillips, and J. Steinert, FCI Normalized Gain, Scientific Reasoning Ability, Thinking in Physics, and Gender Effects, AIP Conf. Proc. 1413, 23 (2012).

[25] E. Brewe, V. Sawtelle, L. H. Kramer, G. E. O'Brien, L. Rodriguez, and P. Pamela, Toward Equity through Participation in Modeling Instruction in Introductory University Physics, Phys. Rev. Phys. Educ. Res. 6, 010106 (2010).

[26] C. T. Richardson and B. W. O'Shea, Assessing Gender Differences in Response System Questions for an Introductory Physics Course, Am. J. Phys. 81, 231 (2013).

[27] M. Lorenzo, C. H. Crouch, and E. Mazur, Reducing the Gender Gap in the Physics Classroom, Am. J. Phys. 74, 118 (2006).

[28] S. Lauer, J. Momsen, E. Offerdahl, M. Kryjevskaia, W. Christensen, and L. Montplaisir, Stereotyped: Investigating Gender in Introductory Science Courses, CBE Life Sci. Educ. 12, 30 (2013).

[29] B. R. Wilcox and H. J. Lewandowski, Students' Epistemologies about Experimental Physics: Validating the Colorado Learning Attitudes about Science Survey for Experimental Physics, Phys. Rev. Phys. Educ. Res. 12, 010123 (2016).

[30] B. M. Zwickl, T. Hirokawa, N. Finkelstein, and H. J. Lewandowski, Epistemology and Expectations Survey about Experimental Physics: Development and Initial Results, Phys. Rev. Phys. Educ. Res. 10, 010120 (2014).

[31] N. G. Holmes, J. Ives, and D. A. Bonn, The Impact of Targeting Scientific Reasoning on Student Attitudes about Experimental Physics, in Physics Education Research Conference Proceedings 2014, edited by P. V. Engelhardt, A. Churukian, and D. L. Jones (American Association of Physics Teachers, Minneapolis, MN, 2014), pp. 119-122.

[32] L. E. Strubbe, J. Ives, N. G. Holmes, D. A. Bonn, and N. K. Sumah, Developing Student Attitudes in the First-Year Physics Laboratory, in Physics Education Research Conference Proceedings 2016, edited by D. L. Jones, L. Ding, and A. Traxler (American Association of Physics Teachers, Sacramento, CA, 2016), pp. 340-343.

[33] B. R. Wilcox and H. J. Lewandowski, Research-Based Assessment of Students' Beliefs about Experimental Physics: When Is Gender a Factor?, Phys. Rev. Phys. Educ. Res. 12, 020130 (2016).
[34] D. Hu and B. M. Zwickl, Framework for Students' Epistemological Development in Physics Experiments, in Physics Education Research Conference Proceedings 2015, edited by A. Churukian, D. L. Jones, and L. Ding (American Association of Physics Teachers, College Park, MD, 2015), pp. 143-146.

[35] D. Hu and B. M. Zwickl, Examining Students' Personal Epistemology: The Role of Physics Experiments and Relation with Theory, in Physics Education Research Conference Proceedings 2017, edited by L. Ding, A. Traxler, and Y. Cao (American Association of Physics Teachers, Cincinnati, OH, 2017), pp. 11-14.

[36] D. Hu and B. M. Zwickl, Examining Student' Views about Validity of Experiments: From Introductory to Ph.D. Students, Phys. Rev. Phys. Educ. Res. 14, 010121 (2018).

[37] R. F. Lippmann, Students' Understanding of Measurement and Uncertainty in the Physics Laboratory: Social Construction, Underlying Concepts, and Quantitative Analysis, Ph.D. thesis, University of Maryland, College Park, 2003.

[38] Physics majors include students who are pursuing either a physics or an engineering physics major.

[39] N. G. Holmes and E. M. Smith, Operationalizing the AAPT Learning Goals for the Lab, Phys. Teach. 57, 296 (2019).

[40] N. G. Holmes and D. A. Bonn, Quantitative Comparisons to Promote Inquiry in the Introductory Physics Lab, Phys. Teach. 53, 352 (2015).

[41] https://www.physport.org/curricula/ThinkingCritically/.

[42] K. N. Quinn, K. L. McGill, M. M. Kelley, E. M. Smith, and N. G. Holmes, Who Does What Now? How Physics Lab Instruction Impacts Student Behaviors, in Physics Education Research Conference 2018, Washington, DC, edited by A. Traxler, Y. Cao, and S. F. Wolf (American Association of Physics Teachers, Washington, 2018).

[43] B. R. Wilcox and H.J. Lewandowski, Improvement or Selection? A Longitudinal Analysis of Students' Views about Experimental Physics in Their Lab Courses, Phys. Rev. Phys. Educ. Res. 13, 023101 (2017).

[44] S. Kanim and X. C. Cid, The Demographics of Physics Education Research, arXiv:1710.02598.

[45] E. Etkina, A. Van Heuvelen, D. T. Brookes, and D. Mills, Role of Experiments in Physics Instruction-A Process Approach, Phys. Teach. 40, 351 (2002).

[46] A. Buffler, S. Allie, and F. Lubben, Teaching Measurement and Uncertainty the GUM Way, Phys. Teach. 46, 539 (2008).

[47] R. Lippmann-Kung, Teaching the Concepts of Measurement: An Example of a Concept-Based Laboratory Course, Am. J. Phys. 73, 771 (2005).

[48] D. Bates, M. Maechler, B. Bolker, and S. Walker, Fitting Linear Mixed-Effects Models Using lme4, J. Stat. Softw. 67, 1 (2015).

[49] R Core Team, R: A Language and Environment for Statistical Computing, $R$ Foundation for Statistical Computing, Vienna, Austria, https://www.R-project.org/.

[50] A. Kuznetsova, P. B. Brockhoff, and R. H. B. Christensen, lmerTest Package: Tests in Linear Mixed Effects Models, J. Stat. Softw. 82, 1 (2017).

[51] K. Barton, MuMIn: Multi-Model Inference, R package version 1.40.4, https://CRAN.R-project.org/package=MuMIn. 
[52] A. Zeileis and T. Hothorn, Diagnostic Checking in Regression Relationships, R News 2, 7 (2002), https://cran .r-project.org/web/packages/lmtest/vignettes/lmtest-intro.pdf.

[53] C. R. Bilder and T. M. Loughin, Testing for Marginal Independence between Two Categorical Variables with Multiple Responses, Biometrics 60, 241 (2004).
[54] N. Bogel-Burroughs, Deer Dies in Cornell Graduate Student Office after Leaping through Rockefeller Hall Window, Cornell Sun, 2017, https://www.cornellsun.com/ 2017/11/16/deer-dies-in-cornell-graduate-student-office-afterleaping-through-rockefeller-hall-window/. 